\title{
FONTES E DOSES DE NITROGÊNIO NA PRODUÇÃO DE MUDAS DE AÇAIZEIRO (Euterpe oleracea Mart)
}

\author{
Jéssica Larissa de Souza Bezerra ${ }^{1}$, Romeu de Carvalho Andrade Neto ${ }^{2}$, Aureny \\ Maria Pereira Lunz ${ }^{2}$, Cleyton Silva de Araújo $^{3}$, Ueliton Oliveira de Almeida ${ }^{4}$ \\ ${ }^{1}$ Mestre em Produção Vegetal pela Universidade Federal do Acre, Rio \\ Branco, Acre, Brasil \\ ${ }^{2}$ Empresa Brasileira de Pesquisa Agropecuária, Rio Branco, Acre, Brasil \\ (romeu.andrade@embrapa.br) \\ ${ }^{3}$ Mestrando Ciência, Inovação e Tecnologia para a Amazônia pela \\ Universidade Federal do Acre, Rio Branco, Acre, Brasil \\ ${ }^{4}$ Doutorando em Produção Vegetal da Universidade Federal do Acre, Rio \\ Branco, Acre, Brasil
}

Recebido em: 06/04/2018 - Aprovado em: 10/06/2018 - Publicado em: 20/06/2018 DOI: 10.18677/EnciBio 2018A50

\begin{abstract}
RESUMO
O açaizeiro é a palmeira mais produtiva da região amazônica, com potencial comercial advindo da crescente demanda pelos seus derivados. É uma cultura exigente em nutrientes, mas pouco estudada quanto à adubação em formação inicial. O objetivo deste estudo foi avaliar os efeitos de fontes e doses de nitrogênio, na produção de mudas de açaizeiro (Euterpe oleracea Mart). O experimento foi instalado e conduzido na Embrapa Acre, em viveiro telado com 50\% de sombra. $O$ delineamento utilizado foi em blocos casualizados, no esquema fatorial $3 \times 5$, com 15 tratamentos, três repetições e seis plantas por parcela, totalizando-se 270 plantas. Os fatores foram três fontes de nitrogênio (ureia, nitrato de cálcio e sulfato de amônio) e cinco doses (0; 450; 900; 1350; e $1800 \mathrm{mg} \mathrm{dm}^{-3}$ ). Após 180 dias foram avaliadas as seguintes variáveis: altura da planta $(\mathrm{cm})$, diâmetro do coleto $(\mathrm{mm})$, massa seca da parte aérea $(\mathrm{g})$, da raiz e total das plantas $(\mathrm{g})$, e índice de qualidade de Dickson. Os dados foram submetidos à análise de variância a $5 \%$ de probabilidade. As médias das fontes foram comparadas pelo teste de Tukey e as doses foram submetidas à análise de regressão. Entre as fontes de nitrogênio utilizadas, a ureia destacou-se ao promover a formação de mudas de açaizeiro de melhores caraterísticas. Doses elevadas de nitrogênio, independente da fonte, levam a efeito a formação de mudas de açaizeiro de má qualidade.
\end{abstract}

PALAVRAS-CHAVE: Amazônia, nutrição mineral, palmeira. 


\section{SOURCES AND DOSES OF NITROGEN IN THE PRODUCTION OF SEEDLINGS OF ASSAI (Euterpe oleracea Mart)}

\section{ABSTRACT}

The assai is the most productive palm of the Amazon region, with commercial potential due the growing demand for its derivatives. It's a culture demanding in nutrients, but there are few studies regarding the nutrition in the initial growing, especially regarding in the stage of seedlings. The objective of this study was to evaluate the effects of nitrogen sources and doses on the production of assai seedlings (Euterpe oleracea Mart). The experiment was installed and conducted at Embrapa Acre, in a nursery with $50 \%$ shade. The design was a randomized complete block design, in a factorial scheme of $3 \times 5$, with 15 treatments, three replications and six plants per plot, totalizing 270 plants. The factors were three sources of nitrogen (urea, calcium nitrate and ammonium sulfate) and five doses $(0,450,900,1350$, and $\left.1800 \mathrm{mg} \mathrm{dm}^{-3}\right)$. After 180 days were evaluated: plant height $(\mathrm{cm})$, collection diameter $(\mathrm{mm})$, shoot dry mass $(\mathrm{g})$, root dry mass and dry mass total $(\mathrm{g})$, and Dickson Quality Index. The means of the sources were compared by the Tukey's test and the doses were submitted to regression analysis at $5 \%$ of significance. Urea was distinguished by promoting the formation of assai seedlings of better characteristics. High doses of nitrogen, regardless of source, lead to the formation of poor quality assai seedlings.

KEYWORDS: Amazon, mineral nutrition, palm.

\section{INTRODUÇÃO}

$\mathrm{Na}$ busca pela agricultura voltada à sustentabilidade, porém sem perder sua característica de alta lucratividade, a exploração de espécies nativas como o açaizeiro, é uma das formas de equalização desses pontos divergentes. A exploração racional dessa palmeira, principalmente na região amazônica, e a aceitação dos seus derivados pelos mercados internos e externos, são a prova do sucesso desse modelo de exploração sustentável. Assim, o uso de produtos florestais não madeireiros como fonte primária de exploração e renda, tem um destaque especial na região amazônica. Logo, o açaizeiro se destaca por seu valor comercial no norte do país, onde são aproveitadas a polpa advinda da maceração do fruto e o palmito retirado de seu estipe, sendo que o suco de açaí se constitui como principal produto da planta, o qual tem ganhado crescente espaço no cenário nacional (NOGUEIRA et al., 2011).

A principal forma de alcançar a regularidade na produção é promover atenção especial a todas as fases do ciclo produtivo da cultura, a começar pela formação das mudas. Uma prática que possibilita a obtenção de mudas de qualidade é a adubação, que pode ser responsável por acelerar o crescimento das plantas no viveiro, reduzir o tempo de produção e, consequentemente, antecipar a produção a campo. Itens como, composição, forma e solubilidade, são alguns dos atributos dos fertilizantes que vêm sendo analisados, alterados e aplicados no manejo das frutíferas (PIAS et al., 2015). Através das adubações química e orgânica são fornecidos os nutrientes que o substrato não oferece, atendendo nutricionalmente a demanda e garantindo maior taxa de pegamento das plantas em campo.

As estratégias de adubação voltadas às fases iniciais do vegetal são indicadas quando se visa celeridade e padronização das mudas produzidas. A disponibilização de adubos nitrogenados é importante, pois fornece nutriente essencial e de caráter limitante no desenvolvimento e crescimento de qualquer cultura (PIAS et al., 2015). 
O nitrogênio $(\mathrm{N})$ é o nutriente mais abundante, constituinte dos aminoácidos, proteínas, bases nitrogenadas, clorofila, hormônios e dentre outras moléculas, sendo absorvido em maiores quantidades pela planta (SILVA et al., 2014). Sua carência na fase de formação das mudas reflete na diminuição do crescimento e desenvolvimento, e afeta o rendimento final das culturas (ZHANG et al., 2012) devido à redução do acúmulo de biomassa total (VIÉGAS et al. 2009). Assim, é necessário adubar o substrato com esse nutriente para obtenção de mudas de qualidade e produções sustentáveis (FREIBERGER et al., 2013; GONÇALVES et al., 2014; VELOSO et al., 2015; SIMÕES et al., 2016). Dessa forma, é importante avaliar a eficiência de fontes e doses de nitrogênio na produção de mudas de açaizeiro de touceira, tendo em vista que os estudos envolvendo tais fatores com essa cultura são escassos na literatura. O objetivo deste trabalho foi avaliar o crescimento inicial e a qualidade de mudas do açaí de touceira, em função de diferentes fontes e doses de nitrogênio.

\section{MATERIAL E MÉTODOS}

O experimento foi instalado e conduzido, no período de junho de 2016 a janeiro de 2017, no viveiro de produção mudas da Embrapa Acre, localizada na Rodovia BR-364, Km 14 (Rio Branco/Porto Velho), coordenadas 101'30"S, 67ํำ'18"W com altitude aproximada de 160 metros. O clima da região, segundo a classificação de Köppen é quente e úmido com temperaturas máxima de $30,9{ }^{\circ} \mathrm{C}$ e mínima de $20,8{ }^{\circ} \mathrm{C}$, umidade relativa de $83 \%$ e precipitação anual de $1,648 \mathrm{~mm}$, com estação seca e chuvosa bem definida. $O$ viveiro é telado e coberto com sombrite de $50 \%$ de sombra.

O substrato utilizado na produção das mudas foi um Argissolo vermelho, o qual foi coletado da camada superficial $(0-20 \mathrm{~cm})$ e submetido a limpeza em peneira, homogeneizado e seco ao ar. O substrato apresentou as seguintes características químicas: $\mathrm{pH}=4,63 ; \mathrm{Ca}=2,51 \mathrm{cmol}_{\mathrm{C}} \mathrm{dm}^{-3} ; \mathrm{Mg}=0,64 \mathrm{cmol}_{\mathrm{C}} \mathrm{dm}^{-3} ; \mathrm{K}=0,11 \mathrm{cmol}_{\mathrm{c}} \mathrm{dm}^{-}$ 3; $\mathrm{H}+\mathrm{Al}=3,14 ; \mathrm{P}=5,77 \mathrm{mg} \mathrm{dm}^{-3} ; \mathrm{SB}=51,06 \%$.

O delineamento experimental utilizado foi em blocos casualizados completos com quinze tratamentos, três repetições e seis plantas por parcela, totalizando-se 270 plantas. Os tratamentos foram dispostos em esquema fatorial $3 \times 5$, sendo três fontes de N (ureia, nitrato de cálcio e sulfato de amônio) e cinco doses ( $0 ; 450 ; 900$; 1350; e $1800 \mathrm{mg} \mathrm{dm}^{-3}$. Todas as doses e fontes de $\mathrm{N}$ foram parceladas três vezes, com intervalos de aplicação em cobertura de 45 dias, com exceção da testemunha.

Como adubação complementar, foram adicionados $3,3 \mathrm{~g} \mathrm{dm}^{-3}$ de cloreto de potássio divididos em três adubações de cobertura, em intervalos fixos de 45 dias após a repicagem e $2 \mathrm{~g} \mathrm{dm}^{-3}$ de superfosfato simples, incorporado ao substrato. As plântulas de açaizeiro ( $E$. oleracea Mart.) utilizadas foram da cv. BRS-Pará, desenvolvida pela Embrapa Amazônia Oriental, as quais foram repicadas, em estágio de "palito", para sacos pretos de polietileno com capacidade de $3,0 \mathrm{dm}^{3}$, colocando-se uma plântula por recipiente. A cada semana foi realizado o controle manual de plantas daninhas. A irrigação foi realizada três vezes ao dia pelo sistema de aspersão intermitente, aplicando o volume de água necessário para manter a capacidade de campo próxima a $75 \%$.

Aos 180 dias após a repicagem, avaliou-se às seguintes variáveis: altura da planta $(\mathrm{cm})$, medida a partir da superfície do solo do recipiente até a emissão do folíolo da folha mais alta, com auxílio de régua graduada; diâmetro do coleto $(\mathrm{mm})$, medido a $01 \mathrm{~cm}$ acima do solo do recipiente, com auxílio de um paquímetro; massa seca da parte aérea (MSPA), massa seca da raiz (MSR) e massa seca total (MST), ENCICLOPÉDIA BIOSFERA, Centro Científico Conhecer - Goiânia, v.15 n.27; p. 543 
obtidas após a lavagem das raízes em água corrente e sua separação da parte aérea. Posteriormente, as partes aéreas e radicular foram acondicionadas em sacos de papel Kraft devidamente etiquetados e submetidas a estufa de circulação de ar forçada a $55^{\circ} \mathrm{C}$, até atingir a massa constante. Após foi feito a pesagem em balança analítica com precisão de 0,0001. Além disso, foi calculado o índice de qualidade de Dickson (IQD), de acordo com a Equação 1.

$$
I Q D=\frac{M S T}{(H / D C)+(\text { MSPAMSR })}
$$

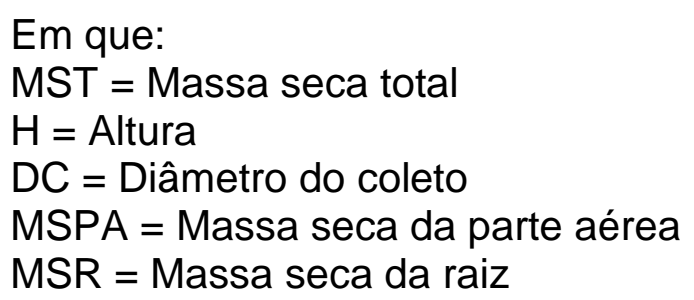

Os resultados foram submetidos à análise de variância (teste $\mathrm{F}$ ), ao nível de $5 \%$ de probabilidade. $\mathrm{O}$ efeito das fontes de nitrogênio $(\mathrm{N})$, quando significativo, foi comparado pelo teste pelo teste de Tukey $(p<0,05)$ e para as doses dos adubos submeteu-se a análise de regressão.

\section{RESULTADOS E DISCUSSÃO}

As fontes, as doses e a interação entre esses fatores influenciaram na altura das plantas de açaizeiro (Tabela 1).

TABELA 1. Análise de variância para a altura da planta (AP), diâmetro do coleto (DC), massa seca das raízes (MSR), massa seca da parte aérea (MSPA), massa seca total (MST) e Índice de qualidade de Dickson (IQD) das mudas de Euterpe oleracea produzidas em função de fontes e doses de adubo nitrogenado. Rio Branco-AC, 2017.

\begin{tabular}{cccccccc}
\hline & \multicolumn{6}{c}{ Quadrado médio } \\
\cline { 2 - 8 } $\begin{array}{c}\text { Fontes de } \\
\text { variação }\end{array}$ & $\mathrm{GL}$ & $\begin{array}{c}\mathrm{AP} \\
(\mathrm{cm})\end{array}$ & $\begin{array}{c}\mathrm{DC} \\
(\mathrm{mm})\end{array}$ & MSR $(\mathrm{g})$ & $\begin{array}{c}\text { MSPA } \\
(\mathrm{g})\end{array}$ & $\begin{array}{c}\text { MST } \\
(\mathrm{g})\end{array}$ & IQD \\
\hline Fonte F & 2 & $34,474^{*}$ & $0,877^{\text {ns }}$ & $0,699^{\mathrm{ns}}$ & $1,209^{\text {ns }}$ & $1,622^{\text {ns }}$ & $0,317^{\text {ns }}$ \\
Dose D & 4 & $158,444^{*}$ & $44,731^{*}$ & $8,472^{*}$ & $21,320^{*}$ & $52,465^{*}$ & $4,360^{*}$ \\
F x D & 8 & $17,209^{*}$ & $2,156^{\text {ns }}$ & $0,991^{*}$ & $2,359^{*}$ & $6,041^{*}$ & $0,510^{*}$ \\
Bloco & 2 & 22,086 & 5,804 & 0,556 & 9,665 & 14,393 & 0,430 \\
Resíduo & 28 & 4,665 & 1,481 & 0,352 & 0,591 & 1,691 & 0,185 \\
\hline CV $(\%)$ & & 9,11 & 10,04 & 22,30 & 16,35 & 18,44 & 24,36 \\
\hline
\end{tabular}

${ }^{*}$ significância a $5 \%$ e ns não significativo de acordo com o teste de $\mathrm{F}$.

O aumento das doses de adubo nitrogenado com nitrato de cálcio e ureia provocaram efeito negativo no crescimento em altura das mudas a partir da primeira dose, diferente do sulfato de amônio que foi após a segunda dose (Figura 1). 


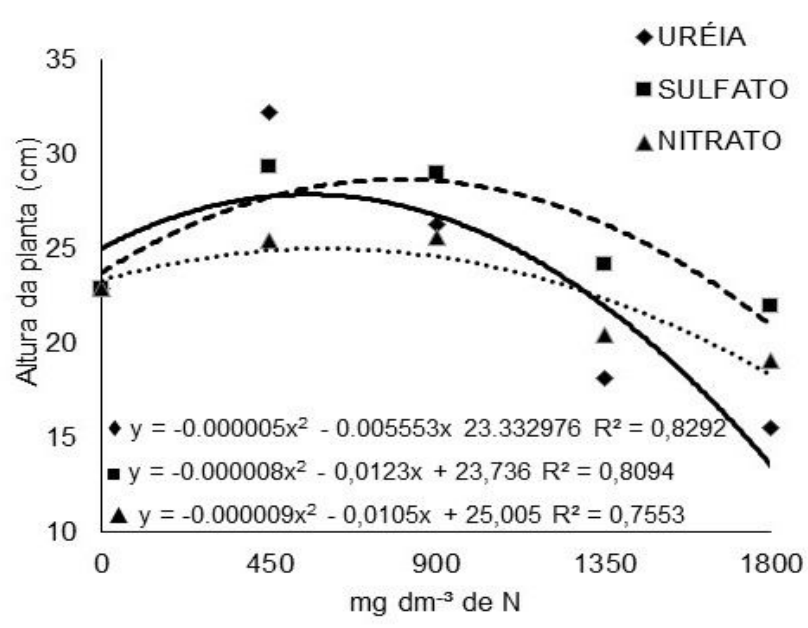

FIGURA 1. Altura da planta de Euterpe oleracea produzidas em função de fontes e doses de adubo nitrogenado. Rio Branco- AC, 2017.

Em todas as fontes avaliadas, o modelo de regressão quadrático foi o que melhor se ajustou à altura da planta, indicando que as doses de $\mathrm{N}$ foram satisfatórias para esta característica, diferente de Oliveira et al. (2011) que obtiveram comportamento linear decrescente com aplicação de ureia em mudas de açaizeiro. A resposta negativa desses autores pode ter ocorrido devido às doses de $\mathrm{N}$ utilizadas serem maiores que a deste estudo.

No caso da ureia, a resposta negativa pode estar relacionada, provavelmente, à acidificação do meio, já que ocorre a conversão da $\mathrm{NH}_{4}{ }^{+}$para $\mathrm{NO}_{3}{ }^{-}$, liberando íons de $\mathrm{H}^{+}$(MALAVOLTA, 1997). O uso do sulfato de amônio também causa acidificação do solo, pois afeta a distribuição e aumenta a lixiviação de $\mathrm{Ca}$ e $\mathrm{Mg}$, o que contribui com a acidez trocável, efeito causado pela liberação de prótons durante a nitrificação do amônio, que ocorre com a aplicação de fertilizantes fornecedores de $\mathrm{NNH}^{-4+}$ (FERRARI et al., 2015). Já o nitrato de cálcio não acidifica o solo, porém, elevadas doses aumenta o $\mathrm{pH}$ da rizosfera devido a rápida absorção do nitrato do que o cálcio pelas plantas (ERNANI, 2003) o que pode ter interferido no crescimento das plantas.

A máxima altura, $28,39 \mathrm{~cm}$, foi obtida com a dose estimada de $766,8 \mathrm{mg} \mathrm{dm}^{-3}$ de sulfato de amônio. Este fertilizante pode ter se destacado em relação aos demais devido à baixa higroscopicidade e a presença de enxofre em sua composição molecular. Welter et al. (2014) encontraram altura de Euterpe oleracea de 21,26 cm, menor que a deste estudo, ao utilizar doses de pó de rocha (basalto), variando o tamanho da partícula, aos 180 dias após a repicagem. Da mesma forma, Oliveira et al. (2011) obtiveram altura inferior para o açaizeiro com uso de ureia. Já Silva et al. (2015) demonstraram que o uso de doses de fertilizante granulado em compostos orgânicos, produzidos a partir de resíduos de agroindústria do palmito de pupunha e lodo de esgoto na produção de mudas de juçara (Euterpe edulis Mart.), reduziu a altura das plantas com o aumento das doses, aos 150 dias após a germinação.

A altura da muda é uma variável que auxilia na classificação das mudas para transplantio, desde que outras características como diâmetro do coleto, massa seca de raízes e número de folhas estejam aptas. Portanto, esse resultado se mostra satisfatório, pois mudas com altura maior tendem a apresentar maior crescimento e desenvolvimento após o transplantio para o local definitivo. Isso se não estiverem estioladas devido a competição por luminosidade (REIS et al., 2016). 
O diâmetro do coleto das mudas de açaizeiro foi influenciado apenas pelas doses de nitrogênio (Tabela 1). O diâmetro máximo obtido foi de $14,06 \mathrm{~mm}$, estimado com a dose de $741,25 \mathrm{mg} \mathrm{dm}^{-3}$ (Figura 2).

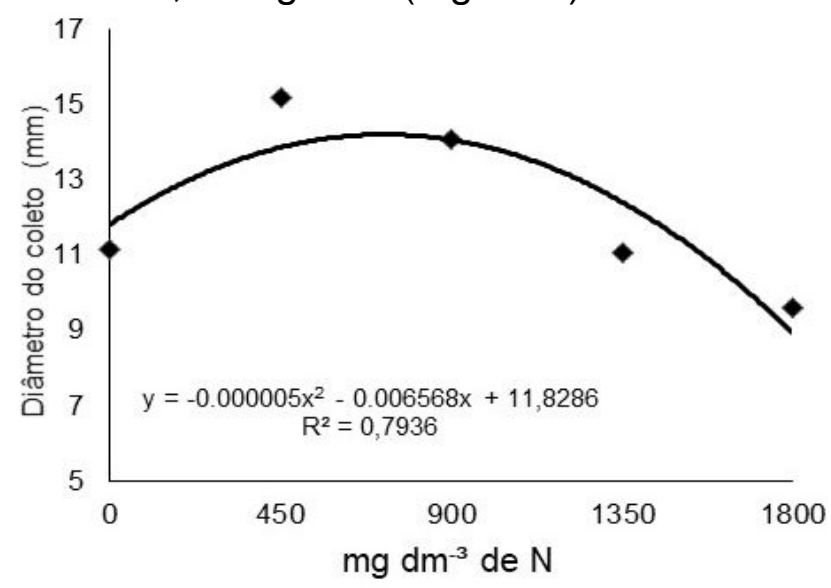

FIGURA 2. Diâmetro do coleto de mudas de Euterpe oleracea produzidas em função de fontes e doses de adubo nitrogenado. Rio Branco-AC, 2017.

Ao avaliarem a influência de nitrogênio sobre o diâmetro do coleto de açaizeiro (Euterpe oleracea) com uso de ureia, no primeiro e segundo ano de idade, Veloso et al. (2015) observaram que tal nutriente interferiu negativamente no primeiro ano, diferentemente deste trabalho. Porém, os autores obtiveram resultados positivos no segundo ano de idade.

$O$ uso de adubos nitrogenados em excesso saliniza o solo, o que pode restringir o crescimento das plantas, caso os íons minerais excedam a zona adequada de um determinado nutriente, ou atinja níveis que venham a limitar a disponibilidade hídrica (TAIZ; ZEIGER, 2017), fato que pode ter contribuído para a redução do diâmetro das plantas nas dosagens mais elevadas.

A massa seca das raízes foi influenciada pelas doses e pela interação entre as fontes e doses de adubo (Tabela 1). O melhor modelo de regressão que se ajustou foi o quadrático para as fontes de ureia e sulfato de amônio, e linear decrescente para o nitrato de cálcio (Figura 3).

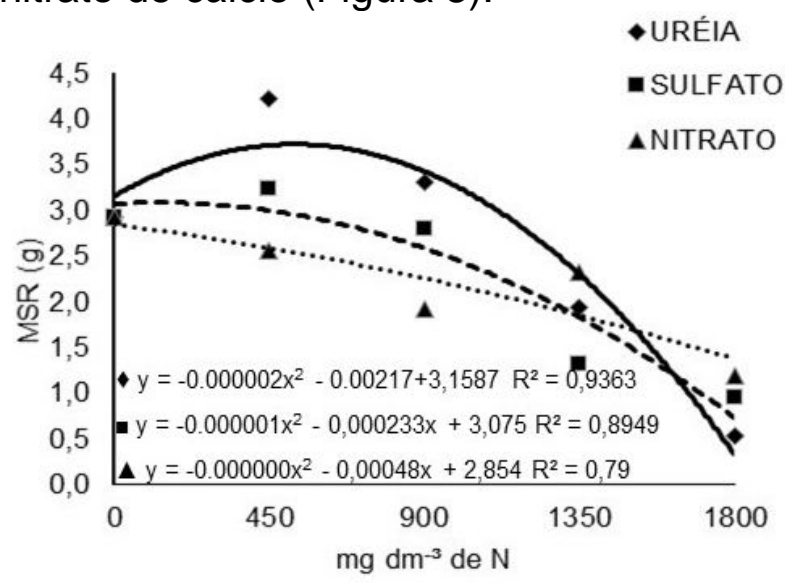

FIGURA 3. Massa seca das raízes (MSR) de mudas de Euterpe oleracea produzidas em função de fontes e doses de adubo nitrogenado. Rio Branco-AC, 2017. 
Simões et al. (2016) também observaram comportamento quadrático para a massa seca das raízes de tachi-branco (Tachigali vulgaris) produzidas em viveiro com uso de ureia. Já Freiberger et al. (2013) obtiveram resultados com comportamento linear positivo para o acúmulo da biomassa das raízes de cedro (Cedrela fissilis VELL.) quando aplicaram doses crescentes de nitrogênio, ao contrário deste estudo.

O acúmulo máximo de massa seca das raízes, $3,5 \mathrm{~g}$, foi alcançado com a dose de $514,29 \mathrm{mg} \mathrm{dm}^{-3}$ de ureia, sendo que as demais fontes reduziram a biomassa radicular das mudas com o aumento das doses. Ciriello et al. (2014) ao verificarem o efeito de doses crescentes de ureia $\left(0,40,80,120\right.$ e $\left.160 \mathrm{mg} \mathrm{dm}^{-3}\right)$ no crescimento inicial de guanandi (Calophyllum brasiliense Cambèss), observaram que a menor dose, $40 \mathrm{mg} \mathrm{dm}^{-3}$, proporcionou maior acúmulo de biomassa radicular dessas mudas, assim como neste trabalho.

A maior massa seca da raiz obtida em com o uso de ureia pode favorecer o desempenho das mudas no campo, pois a sobrevivência e qualidade da planta serão maiores devido à facilidade de sustentação e absorção de nutrientes, uma vez que o sistema radicular é mais expressivo (BONAMIGO et al., 2016). A massa seca da parte aérea das mudas de açaizeiro foi influenciada pelas doses e pela interação das fontes com as doses (Tabela 1), sendo que o modelo que melhor se ajustou foi quadrático, para todas as fontes de adubo analisadas (Figura 4).

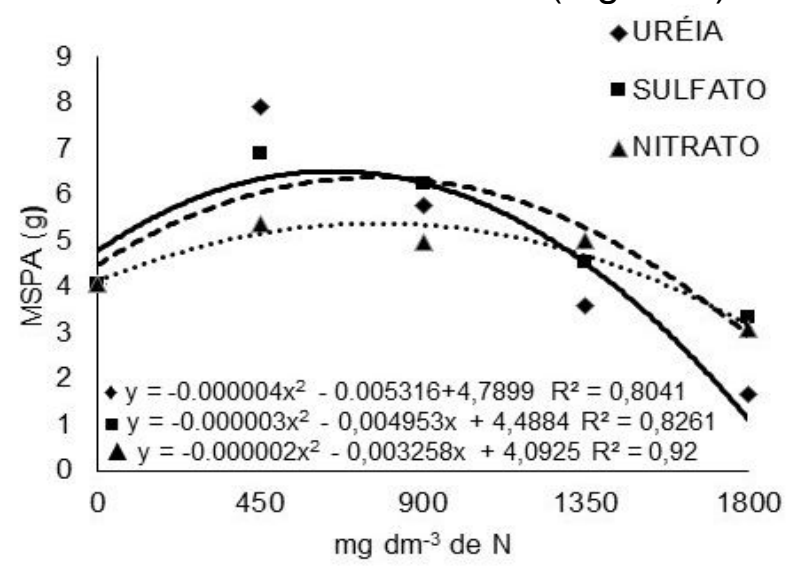

FIGURA 4. Massa seca da parte aérea (MSPA) de mudas de Euterpe oleracea produzidas em função de fontes e doses de adubo nitrogenado. Rio Branco-AC, 2017.

Simões et al. (2016) também observaram comportamento quadrático para mudas de tachi-branco (Tachigali vulgaris) com o uso de ureia e nitrato de cálcio. $\mathrm{O}$ máximo acúmulo de massa seca da parte aérea $(4,78 \mathrm{~g})$ ocorreu com a dose estimada de $664,50 \mathrm{mg} \mathrm{dm}^{-3}$ de ureia. Resultados semelhantes foram encontrados por Welter et al. (2014), que encontraram biomassa seca de parte aérea de $4,19 \mathrm{~g}$ em mudas de açaizeiro Euterpe oleracea.

A massa seca total apresentou efeito significativo para as fontes e para a interação entre fontes e doses de nitrogênio (Tabela 1). O valor máximo de 10,28 $\mathrm{g}$ de massa seca total foi obtido com a dose estimada de $624,41 \mathrm{mg} \mathrm{dm}^{-3}$ de ureia (Figura 5), tendo-se o melhor ajuste pelo modelo quadrático de regressão para todas as fontes usadas, corroborando com os encontrados por Simões et al. (2016) e Gonçalves et al. (2014). 


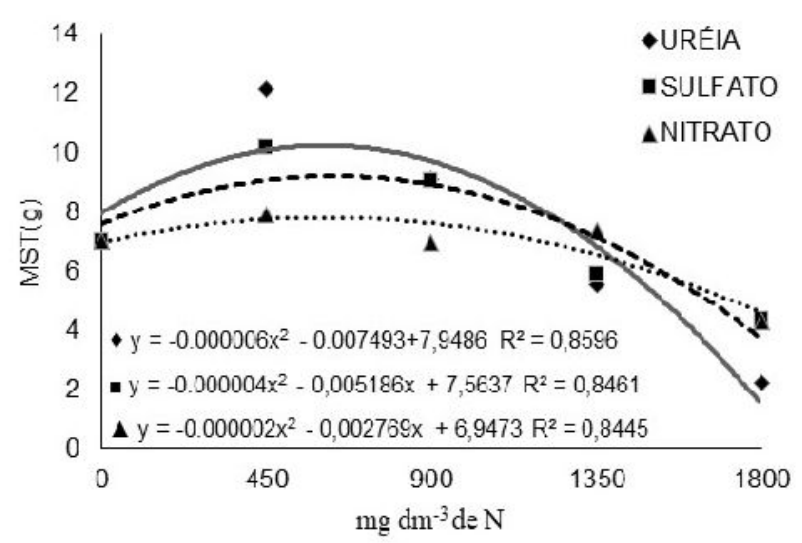

FIGURA 5. Massa seca total (MST) de mudas de E. oleracea produzidas em função de fontes e doses de adubo nitrogenado. Rio Branco-AC, 2017.

Resultados superiores foram obtidos por Dapont et al. (2016) com 14,45 g, estimado com $40 \%$ de sombra em condições de viveiro, em Rio Branco-AC. Entretanto, Welter et al. (2014) encontraram valores de 6,13 g com uso de doses de pó de rocha, inferiores ao deste estudo, provavelmente devido a disponibilidade de nutrientes serem menores e por demorar mais tempo para ficar disponível as plantas. Considerando esses trabalhos, pode-se inferir que a adubação nitrogenada com ureia proporciona mudas com biomassa satisfatória para o transplantio.

$\mathrm{O}$ aumento das doses de nitrogênio no substrato proporciona incremento na massa seca da raiz, da parte aérea e do diâmetro (FREIBERGER et al. 2013), principalmente quando existe deficiência desse nutriente, mas se a aplicação for elevada, o crescimento e desenvolvimento das plantas pode ser prejudicado devido aos impactos negativos exercido na absorção dos demais nutrientes.

O nitrogênio, segundo Viégas et al. (2009), é um nutriente importante para o crescimento de mudas de açaizeiro, visto que a sua omissão reduziu a massa seca das folhas em $49,33 \%$, a massa seca do coleto em $70,75 \%$, a massa seca da parte aérea em $58,98 \%$ e a massa seca total em $42,21 \%$, quando comparado com o tratamento que recebeu todos os nutrientes.

$O$ índice de qualidade de Dickson (IQD) foi influenciado significativamente pelas doses e pela interação entre doses e fontes de nitrogênio (Tabela 1), onde o maior valor obtido foi de 2,67, estimado com a dose $450 \mathrm{mg} \mathrm{dm}^{-3}$ de ureia (Figura 6), indicando que as mudas apresentaram melhor qualidade em relação às demais fontes de $\mathrm{N}$ devido ao maior IQD (GOMES et al. 2002). 


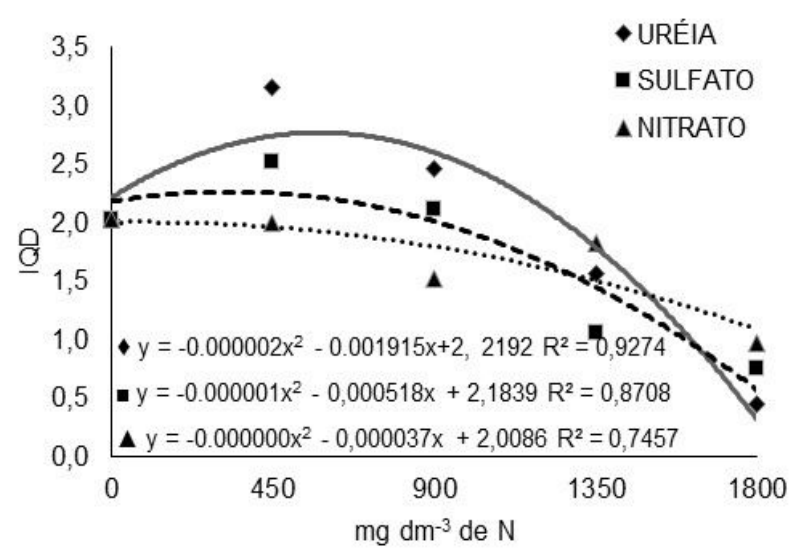

FIGURA 6. Índice de Qualidade de Dickson (IQD) de mudas de Euterpe oleracea produzidas em função de fontes e doses de adubo nitrogenado. Rio Branco-AC, 2017.

Esse resultado é inferior ao valor de 5,4, aos 180 dias após a repicagem, determinado por Welter et al. (2014), em razão do manejo, já que esse índice pode variar conforme a espécie e condições de cultivo, sendo, portanto, necessário realizar estudos de espécies frutíferas para que o IQD seja mais preciso e suficiente para indicar que as mudas estão aptas para o transplantio (REIS et al., 2016).

Silva et al. (2015) encontraram valor de IQD médio de 0,4 para mudas de juçara produzidas com compostos orgânicos. Ao avaliar o uso de ureia em mudas de jaqueira (Artocarpus heterophyllus Lam.) em diferentes doses, Silva et al. (2014) encontraram resposta linear decrescente com o aumento das doses, tendo-se maior IQD 0,6 obtido com a ausência da adubação, diferente deste trabalho que apresentou comportamento quadrático o que possibilitou determinar a dose de adubo nitrogenado.

Segundo Bonamigo et al. (2016), o IQD é uma ferramenta importante para avaliar se as mudas estão aptas para plantio em local definitivo, uma vez que engloba vários parâmetros morfológicos, indicadores de sobrevivência e de qualidade das mudas, como o cálculo da robustez e o equilíbrio de distribuição da biomassa.

\section{CONCLUSÕES}

Entre as fontes de nitrogênio utilizadas, a ureia se destacou ao promover a formação de mudas de açaizeiro com melhor qualidade para transplantio, isto é, praticamente para todas as características avaliadas, exceto altura da muda e diâmetro do coleto.

O açaizeiro responde de forma significativa à aplicação de doses de adubos nitrogenados. Porém, doses elevadas deste nutriente, independente da fonte, levam a efeito a formação de mudas de má qualidade.

\section{REFERÊNCIAS}

BONAMIGO, T.; SCALON, S. de P. Q.; PEREIRA, Z. V. Substratos e níveis de luminosidade no crescimento inicial de mudas de Tocoyena formosa (Cham. \& Schltdl.) K. Schum. (RUBIACEAE). Ciência Florestal, v. 26, n. 2, p. 501-511, 2016. ENCICLOPÉDIA BIOSFERA, Centro Científico Conhecer - Goiânia, v.15 n.27; p. 5492018 
Disponível em: < http://dx.doi.org/10.5902/1980509822750>. doi: $10.5902 / 1980509822750$

CIRIELLO, V.; GUERRINI, I. A.; BACKES, C. Doses de nitrogênio no crescimento inicial e nutrição de plantas de guanandi. Cerne, v. 20, n. 4, p. 653-660, 2014. Disponível em: < http://dx.doi.org/10.1590/01047760201420041445>.

doi:

10.1590/01047760201420041445

ERNANI, P. R.; Disponibilidade de nitrogênio e adubação nitrogenada para a macieira. 71 ed. Lages: Graphel, 2003. 76 p.

FERRARI, S.; FURLANI JÚNIOR, E.; GODOY, L. J. G.; FERRARI, J. V.; SOUZA, W. J. O.; ALVES, E. Effects on soil chemical attributes and cotton yield from ammonium sulfate and cover crops. Acta Scientiarum Agronomy, v. 37, n. 1, p. 75-83, 2015. Disponível em: < http://dx.doi.org/10.4025/actasciagron.v37i1.17972>. doi: 10.4025/actasciagron.v37i1.17972

FREIBERGER, M. B.; GUERRINI, I. A.; GALETTI, G.; FERNANDES, D. M. F.; CORRÊA, J. C. Crescimento inicial e nutrição de cedro (Cedrela fissilis VELL.) em função de doses de nitrogênio. Revista Árvore, v. 37, n. 3, p. 385-392, 2013. Disponível em: <http://dx.doi.org/10.1590/S0100-67622013000300001>. doi: 10.1590/S010067622013000300001

GOMES, J. M.; COUTO, L.; XAVIER, A.; GARCIA, S. L. R. Parâmetros morfológicos na avaliação da qualidade de mudas de Eucalyptus grandis. Revista Árvore, v. 26, n. 2, p. $\quad$ 655-664, 2002. Disponível em: < http://www.scielo.br/pdf/rarv/v26n6/a02v26n6.pdf>. doi: http://dx.doi.org/10.1590/S010067622002000600002

GONÇALVES, E. O.; PAIVA, H. N.; NEVES, J. C. L.; KLIPPEL, V. H.; CALDEIRA, V. W. Crescimento de jacacrandá-da-bahia (Dalbergia nigra ((Vell.) Fr. All. Ex Benth)) sob diferentes doses de NPK. Revista Cerne, v. 20, n. 3, p. 493-500, 2014. Disponível em: < http://dx.doi.org/10.1590/01047760201420031220>.

doi: $10.1590 / 01047760201420031220$

MALAVOLTA, E.; VITTI, G. C.; OLIVEIRA, S. A. Avaliação do estado nutricional das plantas: princípios e aplicações. 2 ed. Piracicaba: Potafós, 1997. 319 p.

MOTA, L. H. S.; SCALON, S. P. Q.; HEINZ, R. Sombreamento na emergência de plântulas e no crescimento inicial de Dipteryx alata Vog. Ciência Florestal, v. 22, n. 3, p. 423-431, 2012. Disponível em: <http://www.scielo.br/pdf/cflo/v22n3/1980-5098-cflo22-03-00423.pdf>. doi: http://dx.doi.org/10.5902/198050986611

NOGUEIRA, A. K. M.; SANTANA, A. C.; GARCIA, S. W. A dinâmica do mercado de açaí fruto do estado do Pará: de 1994 a 2009. Revista Ceres, v. 60, n. 3, p. 324-331, 2011. Disponível em: http://dx.doi.org/10.1590/S0034-737X2013000300004>. doi: 10.1590/S0034-737X2013000300004

OLIVEIRA, C. J. de; PEREIRA, E. W.; MESQUITA, F. O. de; MEDEIROS, J. S. dos. ENCICLOPÉDIA BIOSFERA, Centro Científico Conhecer - Goiânia, v.15 n.27; p. 550 
Crescimento inicial de mudas de açaizeiro em resposta a doses de nitrogênio e potássio. Revista Verde, v. 6, n. 2, p. 227-237, 2011. Disponível em: < http://www.gvaa.com.br/revista/index.php/RVADS/article/viewFile/536/875>.

PIAS, O. H. C. de; BERGHETTI, J. L. S.; CANTARELLI, E. B. Qualidade de mudas de cedro em função da utilização de fertilizantes e recipientes de diferentes tamanhos. Revista Agro@mbiente, v. 9, n. 2, p. 208-213, 2015. Disponível em: < https://revista.ufrr.br/agroambiente/article/viewFile/2210/1586>. doi: 10.18227/19828470ragro.v9i2.2210

REIS, S. M.; MARIMON-JÚNIOR, B. H.; MORANDI, P. S.; OLIVEIRA-SANTOS, C.; OLIVEIRA, B. de; MARIMON, B. S. Desenvolvimento inicial e qualidade de mudas de Copaifera langsdorffii Desf. sob diferentes níveis de sombreamento. Ciência Florestal, v. 26, n. 1, p. 11-20, 2016. Disponível em: <http://www.scielo.br/pdf/cflo/v26n1/0103-9954-cflo-26-01-00011.pdf>. 10.5902/1980509821061.

SILVA, C. P. da; GARCIA, K. G. V.; TOSTA, M. S. da; CUNHA, C. S. M.; NASCIMENTO, C. D. V. do; Adubação nitrogenada no crescimento inicial de mudas de jaqueira. Enciclopédia Biosfera, v. 10, n. 18, p. 174 -180, 2014. Disponível em: < http://www.conhecer.org.br/enciclop/2014a/AGRARIAS/Adubacao\%20nitrogenada.pdfs.

SILVA, F. A. de M.; SOUZA, I. V. de; ZANON, J. A.; NUNUES, G. M.; SILVA, R. B. da; FERRARI, S. Produção de mudas de juçara com resíduos agroindustriais e lodo de esgoto compostados. Brazilian Journal of Biosystems Engineering, v. 9, n. 2, p.109-121, 2015. Disponível em: < http://dx.doi.org/10.18011/bioeng2015v9n2p109121>. doi: 10.18011/bioeng2015v9n2p109-121

SIMÕES, P. H. O.; OLIVEIRA NETO, C. F de; VALE, R. S. do; PALHETA, L. F.; PAULA M. $\mathrm{T}$. de; Crescimento e qualidade de mudas de Tachigali vulgaris em resposta à fontes $\mathrm{e}$ doses de nitrogênio. Espacios, online, v. 37, n. 38, p. 29, 2016. Disponível em: < http://www.revistaespacios.com/a16v37n38/16373829.html>.

TAIZ, L.; ZEIGER, E. Fisiologia vegetal: Nutrição Mineral. 6 ed. Porto Alegre: 2017. 888p.

VELOSO, C. A. C.; SILVA, A. R.; SALE, A. Manejo da adubação NPK na formação do açaizeiro em Latossolo amarelo do nordeste paraense. Enciclopédia biosfera, v. 11, n. 22, p. 2177-2182, 2015. Disponível em: < http://dx.doi.org/10.18677/Enciclopedia_Biosfera_2015_190>. doi: 10.18677/Enciclopedia_Biosfera_2015_190

VIÉGAS, I. J. M. de; MEIRLES, R. O. de; FRAZÃO, D. A. C.; CONCEIÇÃO, H. E. O. da; Avaliação da fertilidade de um latossolo amarelo textura média para o cultivo do açaizeiro no estado do Pará. Revista Ciências Agrárias, n. 52, p. 23-36, 2009. Disponível em: < http://periodicos.ufra.edu.br/index.php/ajaes/article/view/121/16>.

WELTER, M. K.; CHAGAS, E. A.; MELO, V. F.; CHAVES, D. B. Initial growth of açaí seedlings in function of basaltb powder doses. International Journal of Agriculture ENCICLOPÉDIA BIOSFERA, Centro Científico Conhecer - Goiânia, v. 15 n.27; p. 551 2018 
Innovations and Research, v. 3, n. 1, p. 18-26, 2014. Disponível em: < https://www.alice.cnptia.embrapa.br/alice/bitstream/doc/1010768/1/IJAIR763Publishe d.pdf>.

ZHANG, H. J.; DONG, H. Z.; LI, W. J.; ZHANG, D. M. Effects of soil salinity and plant density on yield and leaf senescence of field-grown cotton. Journal of Agronomy, Crop Science, v. 198, n. 1, p. 27-37, 2012. Disponível em: <https://doi.org/10.1111/j.1439-037X.2011.00481.x>. doi: 10.1111/j.1439037X.2011.00481.X 